Revista Eletrônica do Mestrado em Educação Ambiental

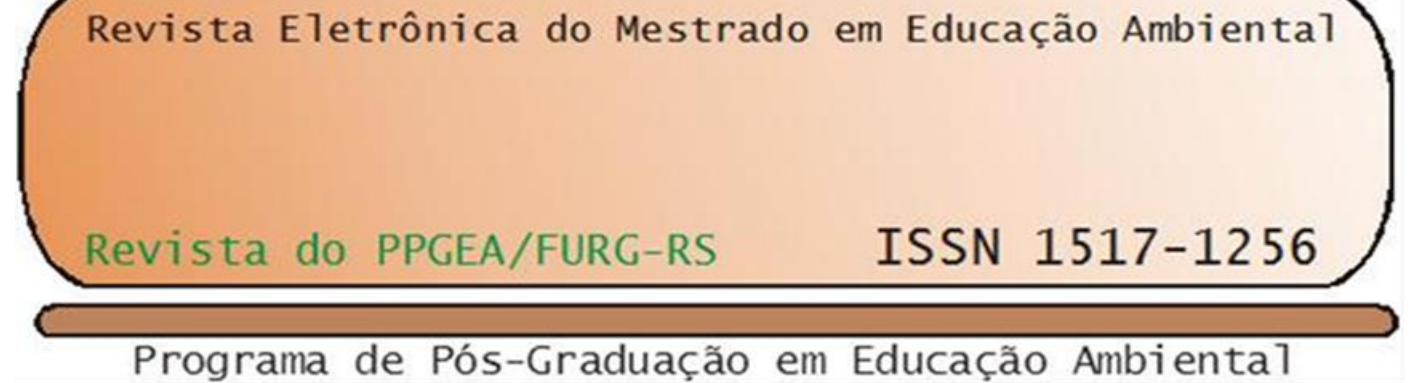

\title{
A atualidade da categoria Diálogo em Freire em tempos de "Escola sem partido"
}

Vilmar Alves Pereira ${ }^{1}$

Graziela Rinaldi da Rosa ${ }^{2}$

Resumo: O diálogo consiste numa categoria que perpassa a história do Pensamento na tradição ocidental. Houve, no entanto, momentos em que os diálogos foram utilizados para dominar. Em outros, para manipular ou persuadir. Em alguns casos esporádicos, para educar, aprender e libertar. Os diálogos não são estabelecidos num vazio. Sempre ocorrem a partir de um contexto. Também não são homogêneos, mas marcados pela pluralidade dos cenários de onde emanam e das ideologias que ali se estabelecem, e procuram dar sentido à vida dos sujeitos que fazem parte desses arranjos existenciais. Após a emergência do Movimento brasileiro "Escola Sem Partido" nos questionamos: existem condições necessárias para o estabelecimento do diálogo com essa prática que se apresenta antagônica em relação aos princípios da educação e sociedade libertária? Em que medida essa face da Pedagogia do Opressor necessita ser reconhecida, compreendida e enfrentada? Após 20 anos da morte de Freire, que inspirações a categoria diálogo como também a sua trajetória nos permitem no sentido de resistirmos e reaprendermos o Brasil da Escola sem Partido? Desse modo, este artigo, num primeiro momento, discorre sobre a importância do diálogo a partir de Freire; num segundo, apresenta a "Escola Sem Partido" como uma das expressões da Pedagogia do Opressor problematizando o papel político da educação e desmitificando a identidade dessa proposta, e uma suposta neutralidade da Educação.

Palavras-chave: Escola Sem Partido. Diálogo. Freire. Pedagogia. Opressor/a.

\section{The nowadays importance of the Dialogue category in Freire in times of "School without party"}

\begin{abstract}
The dialogue is a category that runs through the history of Thought in the Western tradition. There was, however, times when the dialogs were used to rule. In others, to manipulate or

\footnotetext{
${ }^{1}$ Doutor em Educação; professor e pesquisador no Instituto de Educação e nos Programas de Pós-Graduação em Educação (PPGEDU/FURG) e Educação Ambiental (PPGEA/FURG) - Líder do Grupo de Pesquisa do CNPq Fundamentos da Educação Ambiental e Popular (GEFEAP), da Universidade Federal do Rio Grande; editor-chefe da Revista Eletrônica do Mestrado em Educação Ambiental (REMEA). E-mail: vilmar1972@gmail.com

${ }^{2}$ Doutora em Educação pela Universidade do Vale do Rio dos Sinos (UNISINOS/RS); Professora Adjunta do Instituto de Educação da Universidade Federal do Rio Grande. Graduada em Licenciatura Plena em Filosofia e Geografia. Especialista em Metodologia do Ensino. Atua na Formação de Professores/as. Militante do Movimento Feminista e problematiza as Relações de Gênero na Educação e na Filosofia. Integrante da frente em Defesa da Democracia/FURG. Integrante da Frente Gaúcha Escola Sem Mordaça. Coordenadora do Coletivo Feminista Dandara/FURG; Coletivo Pomerano e Núcleo de Estudos Afrobrasileiro e Indígena/NEABI-FURG/SLS. E-mail: grazielarinaldi@furg.br
}

Rev. Eletrônica Mestr. Educ. Ambient. E-ISSN 1517-1256, Edição especial XIX Fórum de Estudos: Leituras de Paulo Freire, p. 91-111, junho, 2017. 
persuade. In some rare cases, to educate, learn and free. The dialogues are not set in a vacuum. They always occur from a context. Also, they are not homogeneous, but marked by the plurality of scenarios from which they emanate and ideologies that they established, and seek to give meaning to the lives of individuals who are part of these existential arrangements. After the emergence of the Brazilian Movement "Escola Sem Partido" (School Without Party) we question ourselves: there are conditions for the establishment of dialogue with this practice that presents itself antagonistic to the principles of education and libertarian society? To what extent this aspect of the Pedagogy of the Oppressor needs to be recognized, understood and addressed? After 20 years of Freire's death, which inspirations the "dialog" category, as well as its trajectory, allow us in order to resist and relearn the Brazil from the "Escola Sem Partido"? Thus, this article, at first, discusses the importance of dialogue from Freire; at second, presents the "Escola Sem Partido" as one of the expressions of the Pedagogy of the Oppressor questioning the political role of education and demystifying the identity of this proposal, and a supposed neutrality of Education.

KEYWORDS: School Without Party. Dialogue. Freire. Pedagogy. Oppressor.

\section{PRIMEIRAS PALAVRAS}

O terreno da educação pressupõe o diálogo como condição imprescindível. Caso contrário, não há educação, há treinamento. Em específico, no caso brasileiro, sabemos que as relações que preponderam em nossa história nem sempre tiveram o diálogo como referencial orientador. Se isso já é difícil quando pensamos a educação formal, imaginem quando nos propomos a estabelecê-lo no bojo das Políticas Afirmativas e da Educação Pública. Atualmente, estamos acompanhando o desmonte das conquistas históricas de nosso país. Estamos vendo políticas públicas, secretarias e ministérios sendo extintos e/ou desmontados. Alguns desses interferem diretamente no andamento de ações no âmbito da Educação e dos Direitos Humanos, como por exemplo, o Ministério de Políticas para Mulheres; da Cultura; da Igualdade Racial e dos Direitos Humanos; Secretaria de Educação Continuada, Alfabetização; Diversidade e Inclusão; Educação do Campo; Educação Quilombola; Educação de Jovens e Adultos. Tais Secretarias e Ministérios têm papéis fundamentais na construção de políticas educacionais que contribuem para olharmos a diversidade na Educação, e incluir temáticas e sujeitos ocultados/as historicamente. Em diálogo com diferentes movimentos sociais, vinha sendo reconhecida a enorme dívida do poder público em relação aos direitos do povo brasileiro, englobando a diversidade de Povos Tradicionais, as mulheres, os pobres e outros sujeitos que ainda sofrem com as desigualdades e as injustiças de nosso país, um território marcado pela colonização. Pensar a fecundidade do diálogo nesse contexto como forma de resistência e de reaprendizagem é o esforço que realizamos a partir de agora. Este texto trata de um diálogo numa perspectiva de descolonização.

A descolonização, como sabemos, é um processo histórico: isto é, ela só 
pode ser compreendida, só tem a sua inteligibilidade, só se torna translúcida para si mesma na exata medida em que se discerne o movimento historicizante que lhe dá forma e conteúdo. A descolonização é o encontro de duas forças congenitalmente antagonistas, que têm precisamente a sua origem nessa espécie de substantificação que a situação colonial excreta e alimenta (FANON, 2005, p. 52).

\section{CONTEXTUALIZAÇÃO DA TEMÁTICA}

Poderíamos iniciar este texto discorrendo sobre inúmeros/as pensadores/as que tiveram no diálogo o elemento propulsor de sua forma de pensar, sentir, ser e agir. Lembramos, no contexto da Grécia, da figura de Sócrates (470 - 399 a.C.), filósofo ateniense, um dos mais importantes ícones da tradição filosófica ocidental que, com sua maiêutica $^{3}$, possibilitava a qualquer pessoa descobrir, pela autorreflexão e pelo exercício da dúvida, que não era possuidora de verdades pré-concebidas. O fundamento da maiêutica é possibilitar, pelo diálogo e pela capacidade de bem perguntar, sobre o quanto ignoramos os contextos quando não nos indagamos sobre eles.

Poderíamos lembrar também, no início da Idade Média, dos diálogos do Filósofo e Teólogo Agostinho. As Confissões, a sua obra de maior interesse literário, é um diálogo contínuo com Deus, em que Agostinho narra a sua vida e, especialmente, a experiência espiritual que acompanha a sua conversão. E o que dizer de Jean-Jacques Rousseau (17121778) e dos diálogos que estabeleceu com a sociedade e a educação de sua época? Rousseau, identificando os equívocos na sociedade civil de seu tempo e na educação tradicional, sugere uma nova cosmovisão social e pedagógica.

Martin Heidegger (1889-1976), filósofo alemão, não quis sair de Friburgo, porque considerava que os grandes interlocutores de seu pensamento eram camponeses, lenhadores da Floresta Negra, com quem mantinha grandes diálogos. Afirmava que ali estavam os pré-socráticos, com pensamentos originários, fora dos ditames da metafísica.

Além desses pensadores, temos as mulheres pensadoras, que compõem esse quadro. Lembramos de Safos de Lesbos (VII-VI a. C.) que dialogava a partir da arte poética; Diotima de Mantineia (427-347 a. C.) pensadora que aparece em "O Banquete", devido seus Diálogos Platônicos. Hipácia de Alexandria (415 d. C.) conhecida por dialogar e lecionar em tempos que as mulheres não podiam se manifestar como seres pensantes.

Durante a Idade Média tivemos Catarina de Siena (1347-1380) uma líder de uma comunidade heterodoxa de homens e mulheres que escreveu Diálogo da Doutrina Divina;

\footnotetext{
${ }^{3}$ Criada por Sócrates no século IV a.C., a maiêutica consiste num método de ensino socrático no qual o professor se utiliza de perguntas que se multiplicam para levar o aluno a responder às próprias questões. É uma técnica de ensino fantástica, que atinge resultados excelentes.
} 
Cristina de Pizan (1365-1431) destacou-se na poesia, ficou conhecida por criticar a misoginia dentro do meio literário e escreveu a obra $A$ Cidade das Mulheres na qual questiona a autoridade masculina de seu tempo.

Na Idade Moderna, Mary Astell (1666-1731), Olímpia de Gouges (1748-1793) e Mary Wollstonecraft (1739-1797) dialogaram pelas causas feministas e direitos das mulheres. Na Idade Contemporânea, Rosa Luxemburgo (1871-1919), conhecida por fundar o Partido Social-Democrata (SPD) da Polônia e Lituânia, dialogava sobre questões da economia capitalista e do proletariado. Hannah Arendt (1906-1975) dedicou-se à ciência política.

Simone de Beauvoir (1908-1986) dialogava sobre um pensamento que ficou conhecido como Existencialismo. Feminista, é reconhecida por renunciar o "eterno feminino" e escrever o livro O Segundo Sexo, mas dialogou sobre outros temas, como a morte, as relações humanas, os lugares por onde viajava, sobre amor, casamento...Em um livro dedicado a Sartre, "A Cerimônia do Adeus" ela dialoga com esse homem, que a deixou um legado de ser a "mulher de", mesmo que fosse mulher dela mesma.

A lista de pensadores/as que concebem o diálogo como fundamento de seu pensar é interminável. Apenas a título de recorte localizamos no Brasil uma referência de grande envergadura em nosso estudo: trata-se de Paulo Freire (1921-1997). Nada mais justo nesse contexto de encolhimento de garantias conquistadas com muitas lutas e tensos diálogos localizarmos Freire a partir dessa mola propulsora em seu pensamento.

\section{Diálogo na Perspectiva de Freire}

A melhor definição para o diálogo, presente inclusive no Dicionário Aurélio, é o antônimo de monólogo, ou seja, dialogar não é simplesmente "conversar" com os/as educandos/as ou membros da comunidade de cocriação, e sim, estar aberto a compreender seus pontos de vista. Na Pedagogia do Oprimido, Freire (2005) afirma que o diálogo só se dá entre iguais e diferentes, nunca entre antagônicos.

Freire aponta para o aspecto que a tradição ocidental, frequentemente sufocadora das condições de diálogos, considerava: estabelecer diálogos, muitas vezes, para ver quem venceria. Nesse caso, o diálogo assume a roupagem apenas de um jogo de perguntas e respostas. Na perspectiva freireana, o diálogo assume outras conotações como veremos.

O diálogo se constrói de forma ética e solidária. A palavra, substrato do diálogo, é o instrumento mais eficaz para a democratização dos saberes, para a resolução de conflitos, para a interação entre os povos e para a consolidação do desenvolvimento cultural, técnico 
e científico que impulsiona o processo civilizatório. Em sua obra Educação como prática de Liberdade, Freire ( 1972, p. 39) diz:

As relações que o homem trava com o mundo (pessoais, impessoais, corpóreas) apresentam uma ordem tal de características que as distinguem totalmente dos puros contatos, típicos da outra esfera animal. Entendemos que, para o homem, o mundo é uma realidade objetiva, independente dele, possível de ser conhecida. É fundamental, contudo, partirmos de que o homem, ser de relações e não só de contatos, não apenas está no mundo, mas com o mundo. Estar com o mundo resulta de sua abertura à realidade, que o faz ser o ente de relações que é.

Esse "estar com o mundo" perpassa pelas relações dialógicas. Conforme Gadotti, “O diálogo é uma relação de unidade de contrários, não antagônicos. Entre antagônicos só pode haver conflitos. Só há diálogo e parceria quando a diferença não é antagônica." (2001, p. 121). Seguindo o mesmo viés de Freire, Gadotti concebe o diálogo não como instrumento de conflito, mas de construção de novas identidades e novos saberes.

Existem sempre no diálogo algumas exigências: todo diálogo pressupõe falar e ouvir. Não existe diálogo só em quem fala, assim como também não existe diálogo só em quem ouve. Mas, sem dúvida, existe o falar e o ouvir, onde o outro fica de fora, ou seja, onde não há abertura para a alteridade. Esta relação, onde se nega a possibilidade do diálogo, deve ser superada. Freire justifica com clareza a afirmação acima, como vemos:

Quem tem o que dizer tem igualmente o direito e o dever de dizê-lo. É preciso, porém, que quem tem o que dizer saiba, sem sombra de dúvida, não ser o único ou a única a ter o que dizer. Mais ainda, que o que tem a dizer não é necessariamente, por mais importante que seja a verdade alvissareira por todos esperada. É preciso que quem tem o dizer saiba, sem dúvida nenhuma, que sem escutar o que quem escuta tem igualmente a dizer, termina por esgotar a sua capacidade de dizer por muito ter dito sem nada ou quase nada ter escutado (FREIRE, 1996, p.116).

Falar, ouvir e sentir, num contexto em que a pluralidade se apresenta como condição inegável, torna-se atualmente um dos maiores desafios. Um dos pontos de clivagem do pensamento tradicional-metafísico foi a formação de um sujeito com capacidade de buscar a unidade e a identidade a partir de estratégias que visavam reunir em si todas as condições para apreensão da realidade. Buscava-se, com isso, a unidade do todo, que negava qualquer forma de multiplicidade.

A dialogicidade que se estabelece entre as diferentes culturas, com as quais convivemos, permite a superação dos limites impostos pelas normas que regem o contexto no qual estamos inseridos. A ruptura das fronteiras advindas pelos cenários globalistas 
impulsiona a multiculturalidade e aprofunda as possibilidades de diálogo entre todos os habitantes da aldeia global. Gadotti, (2001, p.119) com propriedade, salienta que:

A diversidade da cultura é riqueza da humanidade. Pluralismo não significa ecletismo, um conjunto amorfo de retalhos culturais. Pluralismo significa, sobretudo, diálogo com todas as culturas, a partir de uma cultura que se abre às demais. Escola autônoma significa escola curiosa, ousada, buscando o diálogo com todas as culturas e concepções do mundo.

No caso do Brasil, a sociedade está alicerçada na pluralidade cultural. A ética é o fio condutor do diálogo que se estabelece entre as pessoas de diferentes credos e costumes singulares. Nesse contexto, a liberdade para dialogar com as divergências das múltiplas comunidades, para a busca de superação solidária das dificuldades coletivas, deve ser pautada pelo respeito aos propósitos que sustentam as relações entre o homem e a evolução.

Freire, em suas obras, nos chama a atenção para o caso brasileiro no que concerne à ausência do diálogo relacionado com a nossa história recente, na qual, desde o colonialismo, fomos atravessados por profundas relações de subordinação, dominação e exploração. Freire vivenciou isso na carne a ponto ser exilado por 16 anos. Considerava essa experiência uma marca na sua trajetória:

Vocês sabem que houve aquele hiato tremendo entre o $1 .^{\circ}$ de abril de 1964 e o tempo da abertura. Uma das características fundamentais de todo regime de arbítrio é precisamente a tentativa que todos eles têm feito de apagar a história como se eles sentissem a necessidade imensa de começar a história de novo, como se antes deles tudo fosse ruim. Fazem um hiato na história. A juventude do tempo do arbítrio fica proibida de informar-se, de saber o que houve antes do arbítrio. Houve isso no Brasil, obviamente, e uma quantidade enorme de jovens que estão aí hoje com 18,22 anos - alguns não tinham nascido quando houve o hiato, outros eram crianças -, têm uma curiosidade enorme sobre isso. (FREIRE, 2001, p.16-17).

Mesmo tendo sido marcado por relações de poder que sufocavam as possibilidades do diálogo, o conjunto das obras de Freire não se eximia de ver no diálogo uma condição necessária para qualquer relação pedagógica. Nesse sentido, ele entendia que o diálogo deve ser visto como elemento de união, paz e prosperidade; é um valor a ser concebido coletivamente com um único objetivo: a busca da felicidade para todos os seres humanos.

Freire estabeleceu, desde a infância, várias formas de diálogo. Em Cartas a Cristina, afirma que, desde criança, sempre mantinha inúmeros diálogos: com seu quarto escuro, seu relógio pendurado no quarto, seu primeiro quadro de escrever através do qual foi alfabetizado (o chão do terreiro de sua casa); diálogos com sua fome, pois era tanta que, 
muitas vezes, dormia para não senti-la; dialogava sozinho, com as dificuldades que sua família (classe média) passou após a crise de 1929.

Freire teve uma infância muito sofrida. Sentiu muitas necessidades, como a fome, a ponto de em duas ocasiões furtar (um mamão e uma galinha). No entanto, destaca a figura do pai e da mãe como suas referências positivas. O pai, por ser militar e espírita, se negou várias vezes assumir a posição de torturador e, logo, por dificuldades de saúde, tornou-se capitão reformado. A mãe, cristã e católica fervorosa, pela ética e pela labuta frente às dificuldades da vida. Freire enfatiza, nessa época, a liberdade que seu pai e sua mãe sempre lhe proporcionaram inclusive para discordar das formas de subordinação.

Arriscaríamos dizer que a dimensão dialógica está presente em todas as suas obras. Aqui analisamos apenas quatro. A primeira, Cartas a Cristina, por se tratar de uma forma de diálogo quando estava exilado. Freire sempre dialogou com sua sobrinha por cartas. Escrevia a ela semanalmente. A ditadura começou a cercear essa prática. Ele teve, então, que recorrer a amigos de diferentes lugares do mundo para que as cartas chegassem a sua sobrinha por outros remetentes. Em todas, manifestava a saudade pelo país e pela família. Ainda no contexto da negação do diálogo, na obra Pedagogia: diálogo e conflito, como a ditadura havia negado a Freire a possibilidade do diálogo em 20 de novembro de 1978, foi apresentado o seguinte diálogo de Freire aos oitocentos participantes do Primeiro Seminário de Educação Brasileira:

Eu gostaria de dizer aos companheiros, aos amigos que estão aí, agora, no Seminário de Educação Brasileira, da minha emoção imensa, fantástica, que me toma, de estar falando aos professores brasileiros, aos educadores brasileiros, do apartamento em que eu vivo, aqui em Genebra, cercado de meus filhos e de quatro grandes amigos brasileiros que, por coincidência, encontram-se entre nós. É uma alegria enorme me servir da possibilidade que a tecnologia me coloca à disposição, hoje, de gravar, de tão longe de vocês, essa palavra que não pode ser outra senão uma palavra afetiva, uma palavra de amor, uma palavra de carinho, uma palavra de confiança, de esperança e de saudades também, saudade imensa, grandona, saudades do Brasil, desse Brasil gostoso, desse Brasil de nós todos, desse Brasil cheiroso, distante do qual estamos há catorze anos, mas, distante do qual nunca estivemos também. Eu só não estou aí porque, afinal de contas, eu não tenho um passaporte. Faz catorze anos que eu peço esse passaporte não me foi dado. Nem o 'ficaporte', quer dizer, esse extravagante passaporte dentro do qual se escreve que ele é válido só para a cidade onde a pessoa mora, como o 'ficaporte' que deram para a minha mulher. Nem esse eu tenho. E por isso que eu não estou aí, mas espero que um dia eu tenha o 'passa-porte' e aí eu voltarei ao Brasil para abraçá-los e para dizer mais uma vez o quanto brasileiro eu sou, o quanto brasileiro tenho continuado a ser apesar da distância em que estamos no terreno e no espaço (FREIRE, 2001, p.20). 
Ninguém constrói diálogo fora de um contexto. A partir desse cenário é que Freire busca fundamentos para seu pensar, ser e agir. Um cenário de excluídos, tanto pelas dificuldades do seu mundo da vida, quanto pelas contingências e posturas ideológicas políticas. Ler as obras de Freire sem esse contexto é, no mínimo, realizar uma leitura ingênua.

A pergunta é um dos aspectos fundamentais na consecução do diálogo. Freire, na disseminação de sua proposta pelo mundo, afirma que embora as perguntas se apresentem diferentemente vestidas, com roupagens distintas, se têm um turbante na cabeça, então estamos na Índia; se aparecem com uma camisa cheia de cores, calças quadriculadas, estamos nos Estados Unidos... As perguntas são as mesmas, mas sempre diversificadas e caracterizadas em função da cultura, do momento histórico e também, não há dúvida nenhuma, em função da posição de classe de quem as faz. Nesse sentido, ressalta também o caráter de resistência ao novo no ato de perguntar quando a pessoa que pergunta se coloca contra uma possível resposta.

Outro aspecto importante, que está intrínseco na pergunta é o fato de que quem pergunta possui, muitas vezes, uma provável resposta. No entanto, não há como negar que, ao dialogarmos externamos, sim, uma posição política e pedagógica. Ela aparece tanto nas perguntas quanto nas respostas. Nesse sentido, lembra Freire que ser educador traduz uma opção política, como vemos:

Não fazemos essas conferências, palestras, debates e conversas apenas para difundir conhecimentos. Trata-se de fazer um trabalho pedagógicopolítico no sentido de nos conhecermos enquanto educadores; de avançarmos nas respostas às questões que nos colocamos de Norte a Sul desse país (FREIRE, 2001, p.20).

Procurando esclarecer como se dá essa relação entre a dimensão política e a pedagógica, Freire afirma:

Seria uma ingenuidade reduzir todo o político ao pedagógico, assim como seria ingênuo fazer o contrário. Cada um tem a sua especificidade. Mas o que me parece impressionante e dialético, dinâmico, contraditório, é como, mesmo tendo domínios específicos, continua a haver a interpenetração do político no pedagógico e vice-versa (FREIRE, 2001, p.22).

Ciente da relação entre essas duas esferas, Freire chama a atenção para posturas políticas que se encontram no diálogo. Alerta para o fato de que alguns representantes da classe dominante se convertem politicamente às classes dominadas. Ao se converterem às 
classes dominadas, essas pessoas são necessariamente consideradas traidoras da classe dominante, no que estão certas para Freire.

Há, nos diálogos com Freire, uma pergunta que é sempre recorrente: "uma das perguntas fatais, inevitáveis, que recebo, não só aqui, mas em Los Angeles, em Massachusetts, no Michigan, é a seguinte: é possível ou não fazer alguma coisa contra a ordem estabelecida dentro da escola?” (2001, p. 31) Freire a considera uma das questões mais pertinentes e afirma que a mesma exige, no mínimo, uns vinte minutos para contextualizá-la.

Discorrendo ainda no horizonte do estabelecimento da pergunta como uma das condições ao diálogo e questionado sobre a existência ou não de momentos em que tenha perdido a paciência em relação a determinadas perguntas, Freire afirma que, quando recebia questões provocativas, ele aproveitava para exercitar a paciência.

O/a educador/a reacionário/a não permite, em sua metodologia, que o/a educando/a exerça o direito da pergunta. Para Freire, esse tipo de ação controla o/a educando/a pelo poder sobre o método de que o/a educador/ se apropria. Diferente disso, o/a educador/a revolucionário tem no método um caminho de libertação, por isso, na medida do possível, ele discute com o educando/a a apreensão do próprio método de conhecer. Nessa comparação reside a diferença entre treinar e capacitar. Essa última é uma das facetas da educação brasileira que acreditávamos ter superado, mas que surge em momentos onde a onda conservadora e reacionária de um golpe de Estado impõe seu poder. Nesse sentido, cabe-nos analisar a proposta de Lei que ficou conhecida no Brasil como "a Lei da Mordaça", que é totalmente contrária ao diálogo e a uma educação como prática de liberdade. Nesse caso, não há diálogo, há conflito, porque não é possível diálogo entre antagônicos.

\section{3 "ESCOLA SEM PARTIDO": A FACE DESVELADA DA PEDAGOGIA DO OPRESSOR ANTIDIALÓGICA}

A única leitura do mundo, da compreensão da natureza das relações sociais que produzem a desigualdade, a miséria, os sem trabalho, os sem teto, os sem terra, os sem direito à saúde e educação e das questões de gênero, sexo, etnia, cabe aos "especialistas" autorizados, mas não à professora e ao professor como educadores. Decreta-se a idiotização dos docentes e dos alunos, autômatos humanos a repetir conteúdos que o partido único, mas que se diz sem partido, autoriza a ensinar. (FRIGOTTO, 2016, p. 3) 
Miguel Nagib foi o criador da proposta "Escola sem Partido" em 20044. Ele possui atualmente mais de seis mil seguidores em sua página do Facebook e tem criado uma rede que dissemina normas para os professores e professoras. Nas redes sociais, os adeptos à sua proposta compartilham denúncias do que chamam "abuso da liberdade de ensinar e doutrinação política e ideológica em sala de aula”. Encontramos na página no Facebook da escola sem partido cartazes de concurso Nacional sobre a Temática de Gênero "Construindo a Igualdade de Gênero" "5 afixado em escola, prints de perfis de pessoas que se manifestam contra a desconstrução do Estado Democrático, cópias de e-mails pessoais, imagens de cartazes e trabalhos escolares contra preconceito e homofobia, vídeos de estudantes secundaristas protestando contra as atuais reformas e políticas que acabam com Direitos Humanos, e direitos dos/as Trabalhadores/as brasileiros/as brasileiros, reduzindo gastos públicos em áreas como Saúde, Educação e Transporte.

Penna (2016) chama a atenção para o fato de essa "doutrinação político-ideológica" ser o foco do projeto de lei e do "Programa Escola sem Partido", mas não possuir uma definição explícita em nenhum dos artigos do projeto. Para Penna (2016, p. 46) "a ausência da definição da prática que se quer proibir já aponta um gravíssimo problema na formulação do projeto de lei e é um dos elementos de sua inconstitucionalidade".

A "Lei da Mordaça" aparece no Projeto de Lei de no 2974/2014 ${ }^{6}$, no âmbito do ensino no Estado do Rio de Janeiro, em 15 de maio de 2014, e foi proposta pelo vereador Carlos Bolsonaro, que apresentou o projeto, com poucas alterações do dia 03 de junho de 2014 (PL 867/2014) ${ }^{7}$. Dentre outras propostas, Bolsonaro preconizou a "neutralidade política ideológica do Município", "direito dos pais a que seus filhos menores não recebam a educação moral que venha a conflitar com suas próprias convicções". Essa mesma "Lei da Mordaça", com um discurso liberal, traz como bandeira o fim de uma suposta

\footnotetext{
${ }^{4}$ http://www.programaescolasempartido.org/

${ }^{5}$ Esse concurso Nacional possibilitou um amplo e relevante debate nos espaços escolares, pois convidava estudantes do Ensino Médio a pensar sobre questões de gênero nas ciências, nas tecnologias, nas relações interpessoais, e em todos espaços sociais. Possibilitava analisar com jovens as desigualdades de gênero, as violências que as mulheres, homossexuais, transexuais sofrem em nosso país. Para saber mais: http://estatico.cnpq.br/premios/2016/ig/historico.html

${ }^{6}$ Disponível em:

http://alerjln1.alerj.rj.gov.br/scpro1115.nsf/e4bb858a5b3d42e383256cee006ab66a/45741a7e2ccdc50a83257c980062a2c2.

$7 \mathrm{O}$ presente projeto tramita no Âmbito Nacional. Para ler o projeto de lei, acessar: http://mail.camara.rj.gov.br/APL/Legislativos/scpro1316.nsf/f6d54a9bf09ac233032579de006bfef6/5573ae96 1660b4cd83257ceb006bc7d4. Acessado: 23 Out 2016.
} 
"doutrinação política e ideológica em sala de aula" e o lema "minha família, minhas regras ${ }^{8} "$

Art. $2^{\circ}$ É vedada a prática da doutrinação política e ideológica em sala de aula, bem como a veiculação, em disciplina obrigatória, de conteúdos que possam estar em conflito com as convicções morais dos estudantes ou de seus pais. (PL/193, 2016)

Com o lema "Educação sem doutrinação", têm sido propostos alguns deveres ao professor e à professora, tais como: "Não opinar; não demonstrar suas concepções ideológicas" e "Não incitar a manifestações, atos públicos ou passeatas". Esse mesmo conjunto de deveres deixam claro um apelo: "que ao tratar de questões políticas, socioculturais e econômicas, o professor/a apresentará aos 'alunos' "as principais versões teóricas, opiniões e perspectivas", e que "terceiros não podem violar esses direitos nas salas de aulas".

O que está por traz desses deveres? O próprio nome nos remete a normas, obrigações e soa muito parecido com uma doutrinação fascista e antidemocrática. Cabe questionarmos quais sujeitos buscaram-se historicamente emancipar? O que significa emancipação no contexto latino-americano? Há relação entre educação e emancipação? Qual a relação entre educação, construção do sujeito político e emancipação? E ainda, como não contextualizar os conteúdos com acontecimentos históricos negados em nossos currículos?

O conceito de Emancipação precisa ser resgatado. É preciso (re)pensarmos: Como não contextualizar a vida do campo e da cidade nas salas de aula? Como não fazer relação com suas histórias de vidas? Como não dialogar com os movimentos sociais e organizações? Como não discutir temas atuais? Como ser educador/a sem autonomia?

Os conceitos "Cidadania" e "Democracia" roubam as cenas de nossas ruas em meio ao desmonte de políticas públicas, e precisamos perguntar: $\mathrm{O}$ que significa tomar partido de algo? Nas justificativas do projeto de lei "Escola sem Partido", temos a seguinte afirmação:

Nesse sentido, o projeto que ora se apresenta está em perfeita sintonia com o art. $2^{\circ}$ da Lei de Diretrizes e Bases da Educação Nacional, que prescreve, entre as finalidades da educação, o preparo do educando para o exercício da cidadania. Afinal, o direito de ser informado sobre os próprios direitos é uma questão de estrita cidadania. (PL 193/2016) grifo nosso

\footnotetext{
${ }^{8}$ Entende-se família composta pelo pai, a mãe e os/as filhos/as. Uma família patriarcal nos mesmos moldes do século XIX.
} 
Como podemos notar, o entendimento de cidadania é estrito e restringe-se ao ato de alguém ser informado de algo. A cidadania está diretamente ligada à práxis humana e na educação à práxis educativa, que implica reflexão $e$ ação. Não basta que os/as educandos/as recebam informações, eles/as precisam intervir no mundo que vivem. Como afirma Freire, a práxis “é reflexão e ação dos homens sobre o mundo para transformá-lo. Sem ela é impossível a superação da contradição opressor-oprimidos”. (1983, p. 40) Lembramos também que o referido educador acrescenta que:

A realidade social, objetiva, que não existe por acaso, mas como produto da ação dos homens, também não se transforma por acaso. Se os homens são os produtores desta realidade e se esta, na "invasão da práxis", se volta sobre eles e os condiciona, transformar a realidade opressora é tarefa histórica, é tarefa dos homens [e mulheres] (FREIRE, 1983, p. 39).

Sabemos que não existe educação neutra e é justamente contra qualquer neutralidade na educação que a educação, que se propõe ser emancipatória e libertária, é construída. Na Constituição Federal de 1988, mais especificamente no artigo $5^{\circ}$, consta que: "É livre a manifestação do pensamento"; "Ninguém será privado de direitos por motivo de crença religiosa ou de convicção filosófica ou política"; "É livre a expressão da atividade intelectual, artística, científica e de comunicação, independentemente de censura ou licença". No entanto, no contexto social e político que estamos vivenciando no Brasil, encontramos pessoas que se propõem a "Prevenir o abuso da liberdade de ensinar" e incluir nas Diretrizes e bases da Educação Brasileira - LDB nº 9.394, de 20 de dezembro de 1996, o "Programa Escola sem Partido".

Esse Projeto de Lei no 867/2015 - Programa "Escola Sem Partido"-, toma força no Brasil, após o Golpe de 2016, cujo autor é Izalci Lucas, atual presidente da Comissão que analisa a Reforma do Ensino Médio. Isso nos mostra que a "Lei da Mordaça" está diretamente relacionada à Reforma do Ensino Médio e à PEC 241, que também visa, entre outras coisas, tirar o investimento da educação, da saúde e dos transportes, além de outras áreas sociais. Nesse conjunto de ações, estamos acompanhando atos anticonstitucionais e ditatoriais, visto que em nenhum momento a comunidade escolar foi convidada para debater sobre o assunto. Entre outras coisas, o projeto de lei busca alterar o currículo escolar, o exame Nacional do Ensino Médio (ENEM), a oferta e a carga horária das disciplinas9, além de caracterizar a formação de professores/as como tradicional,

\footnotetext{
${ }^{9} \mathrm{O}$ conteúdo obrigatório (de treze disciplinas do Ensino Médio) será diminuído para privilegiar cinco áreas de concentração: linguagens, matemática, ciências da natureza, ciências humanas e formação técnica e profissional.
} 
criminalizando os professores/as que contextualizarem os conteúdos com acontecimentos históricos e sociais.

Além disso, essa Pedagogia Opressora com o lema de que pretende "acabar com a doutrinação Ideológica" considera os/as professores/as como "aliciadores/as". Assim, os/as estudantes poderão denunciar quem "alicia alunos para participar de manifestações, atos públicos, passeatas, etc.”. Nessa tentativa antidialógica de limitar a liberdade, explicita o contexto repressivo e autoritário que está em curso. Trata de um discurso muito parecido com aquele das pessoas que dizem não ser racistas, mas que não são a favor das cotas para os negros/as e indígenas, ou ainda, daqueles/as que não se consideram preconceituosos/as, mas que dizem não gostar de homossexuais ou defendem uma heteronormatividade.

Nessa "Escola sem Partido" como expressão da Pedagogia do Opressor está sendo proposto que os/as estudantes façam denúncias em um "disque denúncia”, caso o/a professor/a "desviar frequentemente da matéria objeto da disciplina para assuntos relacionados ao noticiário político ou internacional”; "Adotar ou indicar livros, publicações e autores identificados com determinada corrente ideológica"; "Exibir aos alunos obras de arte de conteúdo político-ideológico, submetendo-as à discussão em sala de aula, sem fornecer os instrumentos necessários à descompactação da mensagem veiculada e sem dar tempo aos alunos para refletir sobre o seu conteúdo" (Projeto Escola Sem Partido, 2015). A lista de possibilidades do/a estudante denunciar o/a professor/a é grande ${ }^{10}$.

No chão da escola, a esfinge da "Escola sem Partido" e da "Liberdade para ensinar", quebra o que define a relação pedagógica e educativa: uma relação de confiança, de solidariedade, de busca e de interpelação frente aos desafios de uma sociedade cuja promessa mais clara, para as novas gerações, é de" vida provisória e em suspenso". Esta pedagogia de confiança e diálogo é substituída pelo estabelecimento de uma nova função para alunos, pais, mães: dedo-duro. Muito mais grave do que os vinte e um anos de ditadura civil-militar onde os dedo-duro eram profissionais (FRIGOTTO, 2016, p. 3).

Demonstrando que entendem nada de sala de aula e escola, os autores do PL dizem que "nem a escola, nem os professores têm o direito de usar a sala de aula para tratar de conteúdos morais que não tenham sido previamente aprovados pelos pais dos alunos" (Projeto Escola Sem Partido). A educação brasileira havia avançado do que chamamos de

\footnotetext{
10 "Flagrando o Doutrinador" é o título de uma espécie de manual com 17 sugestões de situações, que os/as estudantes possuem para saber em que momento podem denunciar anonimamente o/a professor/a. Fenando de Araújo Penna (2016), em seu artigo "Programa Escola Sem Partido": Uma ameaça a Educação Emancipadora chama atenção para a gravidade do problema.
} 
"educação bancária" e a autonomia do/a professor/a e liberdade de expressão de educandos/as e educadores/as.

Sabe-se que a escola tem um papel fundamental na discussão de temas que, muitas vezes, não são discutidos em casa, e ainda, porque os pais, muitas vezes, não participam das ações que as escolas propõem. Assim:

Para o educador-educando, dialógico, problematizador, o conteúdo programático da educação não é uma doação ou uma imposição - um conjunto de informes a ser depositado nos educandos, mas a devolução organizada, sistematizada e acrescentada ao povo, daqueles elementos que este lhe entregou de forma inestruturada (FREIRE, 1983, p. 98).

Trata de um discurso que nos "transporta" para o século XIX, onde pouco se falava em Direitos Humanos no Brasil. Disponibilizam para a população um "modelo de notificação extrajudicial" e afirmam que trata de um "serviço de utilidade pública". Assim, cabe questionarmos: essa "educação sem partido" está a serviço de quem? Como pensar Gênero, Mulheres e Cidadania nesse contexto? Como propor uma educação que considera a diversidade sexual e de sujeitos quando essa diversidade está ameaçada?

Sabemos que historicamente a educação em nosso país foi voltada para uma parcela da população (rica, branca e do sexo masculino) que teve privilégios durante toda a história da humanidade. Na América Latina, em um país como o Brasil, o branco, europeu e abastado nos deixou a herança do coronelismo, a herança do patriarcado eurocêntrico. Até então a escola sempre teve partido e esteve do lado de quem detinha o poder (brancos ricos e machos). As práticas escolares foram excludentes e conservadoras e não estavam voltadas para emancipação de sujeitos, para exercício da cidadania, da democracia e da libertação de povos. Aliás, não coincidentemente, essas palavras não estão presentes na proposta da "Escola sem partido" de 2016. Afinal, democracia sempre foi uma reivindicação popular e a escola é ainda muito pouco democrática.

A “escola sem partido" como Pedagogia do Opressor defende o silenciamento de sujeitos e o não reconhecimento da liberdade de expressão, por isso está ficando conhecida como "Lei da Mordaça". Ela está totalmente dissociada do que a Constituição Federal de 1988 preconiza, atingindo os direitos fundamentais dessa constituição: como direito de opinião, de expressão, organização e manifestação. Conquistamos a liberdade de expressão e de pensamento, portanto, a liberdade intelectual, artística e científica é um direito do cidadão e da cidadã em uma democracia. Não debater de forma livre em salas de aulas fere os direitos humanos básicos e desrespeita as Diretrizes e Bases da Educação Brasileira. 
Por muito tempo, as estratégias de doutrinação e as ideologias neoliberais e conservadoras estiveram vivas em nossas escolas. Até hoje nossos livros didáticos carregam essa história. As principais versões teóricas e concepções que foram passadas de geração para geração foram as concepções da elite dominante européia. Muito recentemente negros e negras; quilombolas; mulheres; indígenas; povos das comunidades tradicionais começaram a aparecer em salas de aulas, tanto nos bancos escolares, quanto nas falas de professores e professoras. Curiosamente, uma parcela da população tem se incomodado com a presença (nunca antes vista) desses sujeitos nos diferentes setores da sociedade. Essa mesma parcela se admira com a presença de homossexuais e transexuais nas ruas e nas Universidades; são sujeitos que não reconhecem a diversidade, tampouco valorizam a pluralidade cultural.

A compreensão dos limites da prática educativa demanda indiscutivelmente a claridade política dos educadores com relação a seu projeto. Demanda que o educador assuma a política de sua prática. Não basta dizer que a educação é um ato político assim como não basta dizer que o ato político é também educativo. É preciso assumir realmente a política da educação [...] (FREIRE, 1993, p. 46-47) grifo nosso

Compreendemos que a liberdade do professor/a está ameaçada. A "Lei da Mordaça" não contribui para a formação de consciência crítica e de um estado democrático de direito e impede a formação de sujeitos capazes de exercer a sua cidadania. Nesse sentido, essa "escola sem partido", antidialógica se apresenta como um retrocesso da educação brasileira e é um ataque às conquistas e aos avanços que tivemos no campo educacional.

Quem possui uma formação educacional que se preocupa com processos formativos voltados ao empoderamento das camadas populares, a se posicionarem frente aos problemas sociais latino-americanos, a defender uma educação como movimento popular e, ainda, que acredita em uma educação plural, cidadã e justa, em nossa compreensão deve resistir e não aceitar essa mordaça. Nesse horizonte, entendemos que, como forma de resistência, devemos contribuir com a formação política das camadas populares para atuarem na sociedade como processo permanente desde a educação básica. Considerar os diferentes sujeitos (incluindo as mulheres, os/as pobres, negros/as, indígenas, homossexuais, travestis, transexuais) e não os/as silenciar, é papel da escola, sim! Desse modo, somente reconhecendo a diversidade, escutando as histórias de vidas desses sujeitos, 
ouvindo o que eles/as têm a dizer é que iremos contribuir para a "formação cidadã" prevista na LDB (Lei e Diretrizes de base da Educação brasileira).

Entendemos que uma lei que se diz "contra o abuso da Liberdade de Ensinar" é uma afronta para a Educação Popular, pois a liberdade de ensinar não tem limites, já que busca a compreensão da sociedade; consciência crítica da condição de sujeito histórico e político, contribuindo para o despertar da consciência política e como nos disse Freire (1984) a libertação do opressor/a existente em cada um/a de nós; Libertação de todos/as nós!

Esse projeto de lei visa alterar diretamente a LDB, portanto, percebemos uma grande diferença em sua concepção epistemológica, como mostra a imagem abaixo:

QUADRO 1 - Algumas diferenças entre Educação e Instrução a partir da análise da concepção da Escola sem Partido)

\section{EDUCAÇÃO COMO PRÁTICA DE LIBERDADE}

- Qualificação,

- Contribui na formação de sujeitos autônomos e Independentes

- Socialização

- Subjetivação

- Permite que os/as estudantes façam algo

- Cria espaços para que educandos/as se revelem como sujeitos

- Nenhuma educaçãoé neutra

- Representa alguém

- A educação envolve questões sociais, culturais e políticas

- Tornar-se cidadão..protagonista

- Problematiza

- Socializa diferentes saberes

\section{PROPOSTA “ESCOLA SEM PARTIDO”}

- Reprodução
-Individualismo
-Alienação
-Educação Neutra
-Não contribui para coletividade
-Sem criatividade
-Sem senso crítico
-Tentativa de controle
-Não há autonomia
-Não permite independência
-Controla
-Não reconhece a diversidade
-Anula identidades e subjetividades
-Impede problematização
-Exclui
-padroniza

Fonte: [Autor/a]

Nesse sentido, busca-se a Educação do Sujeito Político (Freire) e a Educação como ato Político, levando em conta que tanto o/a educando/a quanto o/a professor/a é um ser inacabado e só pode se reinventar por meio da consciência política. Trata de uma educação que não pode ser neutra e que tem caráter diretivo, objetivo, sonhos, utopias, ideias.

Essa "escola sem partido" vem acabar com qualquer tentativa na educação de construção do sujeito político relacionada com a denúncia de uma sociedade desigual e de Paulo Freire, p. 91-111, junho, 2017. 
injusta, pois carrega em seu cerne o autoritarismo e o silenciamento. Ela é contra uma educação político-libertadora, inquietadora e questionadora, capaz de atuar frente à necessidade de um paradigma emergente, construindo um conhecimento prudente para uma vida decente. (SANTOS, 2001).

A diversidade cultural está ameaçada por esse movimento de "escola sem partido". Temos que lutar por uma escola que pensa o ensino-aprendizagem para a responsabilidade ambiental, política e social. Uma escola que vivencia o saber democrático e participativo para a construção da cidadania, democracia e emancipação e que não pode ser neutra, afinal, nessa escola, as pessoas tomam consciência de si e da sociedade e se posicionam no mundo.

Precisamos acreditar na educação crítica, o que implica levar em conta a prática da cidadania e da democracia. Ambas contribuem para a emancipação e para uma educação viável para as classes populares. Uma educação que promove vivências de solidariedade, fraternidade e democracia na qual professores/as são intelectuais e, portanto, fazem uma leitura crítica do mundo. Afinal, como contribuir em nossa sociedade se não for com uma educação para a decisão e para a responsabilidade política e social? Como não exercer o saber democrático e participativo, se queremos uma sociedade mais humana? Como trabalhar o respeito ao outro, e ensinar a favor da ética, se não aprendemos a ouvir opiniões diferentes das nossas? Como conquistar a equidade de gênero sem olhar para nossos problemas e debater sobre eles? Como possibilitar acesso à cultura sem história e sem leitura de mundo? Como contribuir no fortalecimento da identidade de um sujeito historicamente silenciado, se não damos autonomia para ele/a falar o que pensa?

Assim, a escola é (e deve continuar sendo) um território de lutas e um lugar de esperanças, caso contrário, como seremos educadores e educadoras e contribuiremos para a superação das desigualdades sociais? Como iremos contribuir na formação cidadã?

\section{CONSIDERAÇÕES FINAIS}

Como posso dialogar, se me sinto participante de um gueto de homens puros, donos da verdade e do saber, para quem todos os que estão fora são "essa gente” ou são "nativos inferiores"? (FREIRE, 2005, p.93).

Este texto teve o propósito de apresentar a atualidade e a fecundidade da categoria diálogo em Freire em tempos de "Escola Sem Partido". Também se propôs a identificar no Movimento Escola sem Partido uma das faces identitárias da Pedagogia do Opressor Antidialógica. Desse modo, vimos que a nossa dificuldade de estabelecer diálogo com esse 
movimento está relacionado à sua postura antagônica e excludente das possibilidades de compreensão e entendimento sobre a natureza ontológica de ser professor (a). Compreendemos que, além de uma afronta aos nossos fazeres, há um profundo encolhimento dos sentidos da educação na vida dos sujeitos; que é uma Pedagogia Opressora que incita a raivosidade e o ódio. Superando essa postura entre antagônicos, na Pedagogia do Oprimido, Freire afirma que o diálogo deve ser concebido como condição amorosa:

Não há diálogo, porém, se não há um profundo amor ao mundo e aos homens. [...] O amor é também diálogo... Amor é compromisso com os homens e não uma relação de dominação [...]. Somente rompendo a supressão é possível restaurar o amor. [...] Se não amo o mundo, se não amo a vida, se não amo os homens, não é possível o diálogo (FREIRE, 2005, p.91-92).

Sugere desse modo, pelo diálogo, uma cultura dialógica da não-violência. Uma cultura do diálogo para a inclusão amorosa do ser humano, nas relações que apontam para a alteridade como ponto de partida e de chegada e nunca como meio para dominá-la.

Outra condição, de acordo com Freire, que é imprescindível, é a humildade, pois como afirma: "não há diálogo sem humildade: conversar sobre o mundo não pode ser um ato arrogante. Grandes encontros dos homens sobre sua ação no mundo perdem o sentido se parte deles não possuir a humildade" (FREIRE, 2005, p.92).

Todas essas questões reforçam a premissa do autor de que "auto-suficiência é incompatível com o diálogo". O verdadeiro diálogo se estabelece na humildade e na coragem de colocarmos nossas práticas sob suspeita. Isso tudo indica que dialogamos quando acreditamos numa proposta. A nossa disponibilidade para o diálogo deve partir da confiança que depositamos na perspectiva da escola que não é neutra, mas com ideologias, sim; com enfrentamentos, diferenças; plural e contrária a toda e qualquer forma de opressão.

Freire também aproveita para chamar a atenção para algumas contradições que estabelecemos em nossas práticas discursivas e que são mitos evidentes no Movimento Escola Sem Partido. Em geral, elas apontam para imposturas político-pedagógicas, pois entende que: "Falar em democracia e silenciar o povo é uma farsa (...). Falar em humanismo e negar os homens é uma mentira (...) não existe tampouco diálogo sem esperança" (FREIRE, 2005, p.94).

Contrário a qualquer forma de submissão, subordinação e dominação, o diálogo sugerido por Freire aponta para relações que têm como ponto de partida o respeito pelos 
sujeitos em seus diferentes contextos e reconhece também os saberes oriundos 'do mundo da vida', potencializando-os. Isso pressupõe sensibilidade pelos diferentes:

Aqueles que negam o diálogo (os opressores) atuam sobre os homens para doutrinálos e adaptá-los e não para educá-los. Desse modo, o grande potencial da dialogicidade na educação é a libertação para vencer as condições de opressão nas relações de poder ainda tão cristalizadas pela postura do sujeito que se credibilizou como racional e portador de sentido ao mundo.

Em termos de metodologia, onde se traduz essa dialogicidade? Nos temas geradores. Mas o que é mesmo um tema gerador? "Um universo mínimo temático" (FREIRE, 2005, p.101). De onde emanam os temas geradores? "Será a partir da situação presente, existencial concreta, refletindo o conjunto de aspirações do povo, que poderemos organizar o conteúdo programático da educação ou da ação política" (FREIRE, 2005, p. 100).

O tema gerador não está pronto e deve ser trazido pelos educandos e pelo educador. Freire sugere um buscar temático nos contextos concretos: "O momento desse buscar é que inaugura o diálogo da educação como prática da liberdade" (FREIRE, 2005, p.101). Essa investigação implica, necessariamente, uma metodologia que não pode contradizer à dialogicidade da educação libertadora, portanto, deve ser igualmente dialógica. Respeitando os diferentes sujeitos, Freire acredita que não se trata de ter nos homens objetos de investigação, mas sua compreensão de mundo e linguagem, onde se encontram inseridos e envolvidos com seus temas geradores.

Dada a pertinência dessas inquietações, o diálogo como categoria de resistência, além de uma exigência, deve se apresentar como condição necessária para o estabelecimento e fortalecimento da identidade das escolas em diferentes contextos. Tratase de um processo em construção, aberto ao novo. Os resultados desses diálogos demonstram o quanto o Movimento Escola Sem Partido é antagônico e limitador das potencialidades educativas. Quando Freire retornou do exílio, ele afirmava que era necessário após a ditadura ter que reaprender o Brasil. Consideramos que após o golpe vivenciado no Brasil e estudarmos mais essa face da Pedagogia do Opressor, faz-se necessário o exercício de mais duas categorias propiciadas pelo diálogo: reaprender e resistir. Esta foi uma das intenções deste estudo: demonstrar que isso é possível, a fim de que possamos vencer toda e qualquer tentativa de subordinação planejada pelo opressor. Vivenciamos um tempo em que conhecemos bem as marcas de ser oprimido, faz-se necessário que estudemos a Pedagogia do Opressor e que possamos dialogar contra a 
"Escola Sem Partido", essa "Lei da Mordaça”. Esses elementos reforçam o quanto o Pensamento de Paulo Freire, no ano que lembramos 20 anos de sua morte, nos serve de referência para uma Pedagogia da Contra Marcha como Capacidade de Resistência em tempos de (des)governo em nosso país.

\section{REFERÊNCIAS}

BEAUVOIR, Simone de. A Cerimônia do Adeus. Rio de Janeiro: Nova Fronteira, 1982.

BEAUVOIR, Simone de. Cartas a Nelson Algren - Um amor Transatlântico 19471964. Rio de Janeiro: Nova Fronteira, 2000.

FANON, Frantz. Os Condenados da Terra. Juiz de Fora: Ed. UFJF, 2005.

FREIRE, Paulo. Pedagogia do oprimido. 47. ed. Rio de Janeiro: Paz e Terra, 2005.

FREIRE, Paulo. Cartas a Cristina: reflexões sobre minha vida e minha práxis. Org. Ana Maria Araújo Freire. 2.ed. São Paulo: UNESP, 2003.

FREIRE Paulo; GADOTTI, Moacir; GUIMARÃES Sérgio. Pedagogia: diálogo e conflito. 6.ed. São Paulo: Cortez, 2001.

FREIRE Paulo. Pedagogia da autonomia: saberes necessários a prática educativa. São Paulo: Paz e Terra, 1996.

FREIRE, Paulo. Pedagogia da Autonomia: Saberes necessários à prática educativa. 25.ed. São Paulo: Paz e Terra, 1999.

FREIRE, Paulo. Política e Educação. São Paulo: Cortez, 1993.

FREIRE, Paulo. Pedagogia da Autonomia: Saberes necessários à prática educativa. 25.ed. São Paulo: Paz e Terra, 1996.

FREIRE, Paulo. Pedagogia da Indignação: cartas pedagógicas e outros escritos. São Paulo: Editora UNESP, 2000.

FREIRE, Paulo. Pedagogia do oprimido. 13. ed. Rio de Janeiro: Editora Paz e Terra, 1984.

FREIRE, Paulo. Pedagogia do oprimido. Rio de Janeiro: Editora Paz e Terra, 1983.

FREIRE, Paulo. Educação e Mudança. Rio de Janeiro: Paz e Terra, 1979.

FREIRE, Paulo. Educação como Prática da Liberdade. Rio de Janeiro: Paz e Terra, 1971.

FRIGOTTO, Gaudêncio. “Escola sem partido”: imposição da mordaça aos educadores. Disponível em: < http://www.pagina13.org.br/educacao-2/escola-sem-partido-imposicaoda-mordaca-aos-educadores/> acessado em: 11/10/2016.

PACHECO, Juliana $\left(\mathrm{Org}^{\mathrm{a}}\right)$. Mulher \& Filosofia: as relações de gênero no pensamento filosófico. Porto Alegre: Editora Fi, 2015.

PENNA, Fenando de Araújo Penna. Programa "Escola Sem Partido": Uma ameaça a Educação Emancipadora. In.: GABRIEL, Carmem Teresa; MONTEIRO, Ana Maria; MARTINS, Marcus Leonardo Bomfim (Orgs.). Narrativas do Rio de Janeiro nas aulas de História. Rio de Janeiro: Mauad X, 2016, p. 43-58. 
PEREIRA, Vilmar Alves; DIAS, José Roberto de Lima; TELMO, Paula. Educação

Popular e a Pedagogia da Contra Marcha: uma homenagem a Gomercindo Ghiggi. 1. ed. Passo Fundo: Méritos, 2013.

PROJETO DE LEI 867/2014. Rio de Janeiro. Disponível em:

<http://mail.camara.rj.gov.br/APL/Legislativos/scpro1316.nsf/f6d54a9bf09ac233032579de 006bfef6/5573ae961660b4cd83257ceb006bc7d4>. Acesso em: 23 outubro 2016.

PROJETO DE LEI 2974/2014. Rio de Janeiro. Disponível em:

$<$ http://alerjln1.alerj.rj.gov.br/scpro1115.nsf/e4bb858a5b3d42e383256cee006ab66a/45741 a7e2ccdc50a83257c980062a2c2.> Acesso em :23 Nov 2016.

ROSA, Graziela Rinaldi da. As Relações de Gênero na Filosofia. Santa Cruz do Sul: EDUNISC, 2012.

SANTOS, Boaventura de Sousa. A crítica da Razão Indolente: contra o desperdício da experiência. São Paulo: Cortez, 2001.

SOARES, Leôncio; GIOVANETTI, Maria Amélia; GOMES, Lima Lino (Org.) Diálogos na Educação de Jovens e Adultos. 2.ed. Belo Horizonte: Autêntica, 2006.

STRECK, Danilo Romeu; ESTEBAN, Maria Teresa (Orgs.). Educação Popular: Lugar de construção social coletiva. Petrópolis, RJ: Vozes, 2013.

STRECK, Danilo Romeu.; REDIN, Euclides; ZITKOSKI, Jaime José (Org.). Dicionário Paulo Freire. Belo Horizonte: Autêntica Editora, 2008. 